\title{
SABERES COMPARTILHADOS NO ENSINO DE JOGOS E BRINCADEIRAS: MANEIRAS/ARTES DE FAZER NA EDUCAÇÃO FÍSICA'
}

\author{
MS. JÚLIA MIRANDA FALCÃO \\ Mestre em Educação Física pelo Programa de Pós-Graduação em Educação Física (PPGEF) do \\ Centro de Educação Física e Desportos (CEFD) da Universidade Federal do Espírito Santo (UFES), \\ Pesquisadora do PROTEORIA (Vitória - Espírito Santo - Brasil) \\ E-mail: juliamfalcao@gmail.com

\section{DRA. SILVANA VENTORIM} \\ Professora do Programa de Pós-Graduação em Educação (PPGE) do Centro de Educação \\ (CE) da Universidade Federal do Espírito Santo (UFES), Doutora em \\ Educação pela Universidade Federal de Minas Gerais \\ Pesquisadora do PROTEORIA (Vitória - Espírito Santo - Brasil) \\ E-mail: silventorim@hotmail.com

\section{DR. WAGNER DOS SANTOS} \\ Professor do Programa de Pós-Graduação em Educação Física (PPGEF) do Centro de \\ Educação Física e Desportos (CEFD) da Universidade Federal do Espírito Santo (UFES), \\ Doutorado em Educação pela Universidade Federal do Espírito Santo \\ Pesquisador do PROTEORIA (Vitória - Espírito Santo - Brasil) \\ E-mail:wagner@proteoria.org

\section{DR. AMARÍLIO FERREIRA NETO} \\ Professor Programa de Pós-Graduação em Educação Física do Centro de Educação Física e \\ Desportos (CEFD) da Universidade Federal do Espírito Santo (UFES), Doutorado em \\ Educação pela Universidade Metodista de Piracicaba \\ Coordenador do PROTEORIA (Vitória - Espírito Santo - Brasil) \\ E-mail: amarilio@proteoria.org
}

\section{RESUMO}

O presente texto descreve um projeto pedagógico para o ensino da Educação Física, desenvolvido a partir do conteúdo jogos e brincadeiras, em uma escola municipal de ensino fundamental, com uma turma do $4^{\circ}$ ano. Assume a perspectiva dos estudos com os cotidianos e utiliza, como instrumentos para produção dos dados, a observação, o registro fotográfico e filmico e a entrevista. Justifica a possibilidade de construção de uma prática docente mediada por uma pesquisa colaborativa no espaço-tempo escolar, no processo de compartilhar as práticas pedagógicas reconhecendo a complexidade, a pluralidade e a singularidade das ações escolares, em especial as produzidas nas aulas de Educação Física.

PALAVRAS-CHAVE: Educação física; jogos; brincadeiras; saberes compartilhados.

I. O presente trabalho contou com auxílio financeiro FACITEC (modalidade bolsa de mestrado). 
As aproximações com os cotidianos escolares ${ }^{2}$ têm revelado a necessidade de pesquisas de intervenção na Educação Física, que compartilhem as práticas pedagógicas a partir do seu lugar de produção, compreendendo-as como produtoras de conhecimento, (re)valorizando fazeres, criados e recriados nos espaços-tempos escolares, pelos sujeitos que os constituem. ${ }^{3} \mathrm{O}$ interesse está em focalizar o olhar para o que é feito, trazendo à tona as tantas relações tecidas cotidianamente e que, por vezes, ficam silenciadas. ${ }^{4}$

Diante desse contexto, buscamos, neste artigo, dar visibilidade ao currículo praticado com o cotidiano, ${ }^{5}$ dedicando especial atenção aos saberes tecidos de maneira compartilhada com a professora de Educação Física da Escola Municipal de Ensino Fundamental "Experimental de Vitória/Universidade Federal do Espírito Santo (EMEFEV/UFES)", com as crianças do $4^{\circ}$ ano matutino e com os pesquisadores. De maneira geral, apresentamos, ao mergulhar/intervir nos diferentes espaços escolares, os movimentos de partilhas, negociações e tessituras das redes (CARVALHO, 2009; FERRAÇO, 2008) curriculares produzidas no ensino fundamental.

O estudo torna-se significativo por efetivar um processo conjunto de ensino, pesquisa e formação entre a universidade e a escola, cujo vínculo foi um dos principais

2. Optamos pelo uso do termo "com" por seu significado político-epistemológico ao instituir que dois ou mais sujeitos, em diálogo ou polílogo, constroem saberes com a escola, com o que está fora da escola, com a vida, com o mundo (ALVES; GARCIA, 2008).

3. Essa é uma perspectiva de estudo que tem orientado a produção acadêmica do Instituto de Pesquisa em Educação e Educação Física (PROTEORIA). Em linhas gerais, buscamos compreender, por meio de estudos com o cotidiano escolar, temas relacionados com a formação de professores, com a apropriação e a transformação dos saberes compartilhados na instituição educacional, com os currículos praticados nas aulas de Educação Física e com os processos avaliativos vivenciados nos contextos cotidianos. Sobre o assunto, ver Locatelli (2007), Nunes (2007), Santos, Nunes e Ferreira Neto (2009) e Santos (2005, 2008).

4. Molina Neto e Molina (2009) apontam que grande parte dos pesquisadores, além de pouco jeito e vontade política para entrar em uma escola, quando o faz, avalia o trabalho do professorado, as capacidades físicas, os hábitos de vida e o desenvolvimento motor dos estudantes, ao invés de compreender o que fazem os sujeitos escolares e o sentido da Educação Física no processo educativo. São tímidas as pesquisas que se propõem a compartilhar fazeres no intuito de sinalizar outras possibilidades de ensino, de aprendizagem e de pesquisa para a Educação Física no contexto escolar, prevalecendo os estudos sobre o cotidiano (FERRAÇO, 2003). Ver também Molina Neto e Molina (20 I 0) e Santos (2005, 2008).

5. Nessa perspectiva, o currículo é assumido como redes de saberes-fazeres tecidas na complexidade do cotidiano escolar. Portanto, o interesse está em contribuir para os discursos a favor dos usos que os sujeitos fazem do currículo nos processos de tradução, negociação e mímicas das enunciações culturais. Isso significa assumir os sujeitos das escolas em seus diferentes espaços-tempos de existência como protagonistas, praticantes e realizadores da rede de poderes-saberes-fazeres (OLIVEIRA, 2005). 
desafios, exigindo relações de confiança, de parceria e de diálogos. Participamos da construção desse projeto coletivo, colocando-nos à disposição para, a partir dos problemas e possibilidades encontrados nos fazeres ${ }^{6}$ pedagógicos diários, criar, inventar, negociar outros possíveis para/na Educação Física.

Ao direcionar o foco para o contexto escolar, compartilhando as variáveis e os significados constitutivos das práticas pedagógicas da professora e das crianças de maneira colaborativa, adotamos a perspectiva de pesquisar com o cotidiano. Essa opção nos exigiu a noção de cotidiano como espaço em que se materializam de forma complexa as estratégias e as táticas dos praticantes (CERTEAU, 1994), lugar em que se formam as redes de relações que aparecem e desaparecem nos espaços-tempos subjetivos das escolas.

Mergulhamos no cotidiano entendendo que os autores da vida escolar, ao fazerem uso dos conhecimentos, criam estilos próprios de ensinar, imprimindo formas, grafias de saber e de fazer, construindo uma maneira pessoal e coletiva de agir. Buscamos transcender "o lugar próprio de autoria individualizada rumo a um projeto estratégico/tático de criação coletiva." (CARVALHO, 2009, p. I 64).7

Nesse caso, procuramos nos afastar da visão que reduz o currículo e a formação como prescrição de documentos ou propostas, assumindo como base as redes de fazeres tecidas na/com a complexidade do cotidiano escolar por meio das experiências ${ }^{8}$ produzidas e apropriadas ${ }^{9}$ pelos autores/atores da EMEF "Experimental de Vitória/UFES".

A estruturação do projeto de ensino foi produzida à medida que o processo se materializava, acompanhando sistematicamente o movimento em torno dos fenômenos ocorridos com os praticantes escolares. Para tanto, acompanhamos, por 22 semanas, no período de 12 de fevereiro a 7 de julho de 2009, um total de 58

6. Para Schneider et al. (2009, p.78), "o fazer remete a um conjunto de práticas que são materializadas no cotidiano das aulas, na escola e na rua, mas também a um conjunto de enunciados discursivos sobre a forma de fazer uso dos saberes que são compartilhados pela Educação Física no ambiente escolar."

7. De acordo com Certeau (1994, p. 105), é primordial a relação entre estratégias e táticas, pois "o estudo das táticas cotidianas presentes não deve, no entanto, esquecer o horizonte de onde vem, nem, tampouco, o horizonte para onde deveria ir."

8. Bondía (200 I) afirma que a informação é contrária à experiência; que informação é o que acontece, enquanto a experiência é o que nos acontece. A experiência é uma relação com algo que se experimenta, que se prova, ou seja, "se adquire no modo como alguém vai respondendo ao que Ihe vai acontecendo ao longo da vida e no modo como vamos dando sentido ao acontecer do que nos acontece." (BONDIÁ, 200 I, p. 27).

9. Conforme destaca Certeau ( 1994), no processo de apropriação, os praticantes desenvolvem ações, fabricam formas alternativas de uso, tornando-se produtores, disseminando alternativas, manipulando, ao seu modo, os produtos e as regras. 
aulas realizadas com 25 alunos de sexo masculino e feminino do $4^{\circ}$ ano matutino, e 18 encontros de planejamento com a professora. ${ }^{10}$

Nosso processo de pesquisa caminhou no sentido de dar visibilidade à complexidade dos processos de planejamento, de intervenção, de reflexão, que foram tecidos no próprio ato de projetar o estudo, sendo necessário inventar mil maneiras de caça autorizada ao objeto (CERTEAU, 1994), como a observação, o registro fotográfico e fílmico e a entrevista.

Assim, na estruturação que se segue, este texto se constitui como uma narrativa sobre os fazeres-saberes pedagógicos, construídos no ensino de jogos e brincadeiras, atendo-se aos aspectos didático-pedagógicos mobilizados no processo de ensino, a partir de uma relação coletiva com os sujeitos da escola, especialmente nas aulas de Educação Física.

\section{JOGOS E BRINCADEIRAS: COMPARTILHANDO SABERES}

Iniciamos nossa entrada na escola buscando nos aproximar da professora para refletir sobre as ações e práticas cotidianas. Com os primeiros contatos estabelecidos, começamos a delinear as ações que seriam compartilhadas e a prática de ensino voltada para $\circ 4^{\circ}$ ano. Ao mesmo tempo nos informamos, em entrevista realizada com a professora, sobre as atividades educativas cotidianas, suas características e seus significados, sobre as condições de vida dos sujeitos escolares e a relação com as aulas de Educação Física.

Mediante as narrativas produzidas na entrevista, realizamos encontros de planejamento em que foram problematizadas questões referentes à prática de ensino na Educação Física, como: definição de conteúdos, procedimentos metodológicos, práticas avaliativas, pesquisa como elemento articulador da prática docente e discente. Esses encontros se configuraram como momentos de projeção, partilhas e negociações, em que discutíamos a prática pedagógica, articulando a (re)construção do trabalho docente.

Sobre esse assunto, é preciso ressaltar que a escolha do conteúdo Jogos e brincadeiras foi feita pela própria professora, considerando-o conhecimento socialmente produzido que deve ser aprendido, assistido, refletido e modificado, de modo a promover a ampliação do universo motor e cultural dos alunos. A partir de nossas conversas iniciais, propusemos a possibilidade da constituição de uma prática de ensino articulada a obras de artes que tematizavam o brincar. Essa opção fomentou a problematização de formas interdisciplinares e, ao mesmo tempo,

10. Destacamos que cinco dos encontros de planejamento contaram com a participação da pedagoga. 
permitiu uma inter-relação entre produção, leitura de imagens e contextualização histórica, favorecendo a importância do brincar e do criar nas atividades de Educação Física.

Fizemos uma primeira aproximação ao quadro de Pieter Bruegel, Jogos Infantis, " embora a professora conhecesse outras obras que retratavam brincadeiras, como é possível notar no seguinte relato: "tem uns quadros de pintores que retratam brincadeiras e, se olharmos as suas datas, praticamente, são as mesmas brincadeiras dos nossos tempos" (PROFESSORA DE EDUCAÇÃO FÍSICA, 26-2-2009). Desenvolvemos, ainda, com a professora, na biblioteca da escola, uma pesquisa em que encontramos novas obras de Pieter Bruegel sobre o tema, bem como a produção de outros artistas, como Cândido Portinari e Orlando Teruz. ${ }^{12}$ Com base nessas fontes, resolvemos analisar detalhadamente o quadro Jogos Infantis para usá-lo nas aulas. Essa opção se justificou pela quantidade de jogos e brincadeiras presentes na obra e pela riqueza de detalhes apresentada pelo autor.

Diante do quadro do Bruegel, identificamos as atividades presentes e a relação entre a data, seu contexto original e as brincadeiras existentes em nossa realidade. De fato, não conseguimos visualizar as 84 brincadeiras sinalizadas por Rosa (200 I), porém, nas identificadas, observamos que estão presentes na atualidade, portanto, é possível trabalhar com elas como conteúdos de ensino nas aulas.

As iniciativas, em relação ao ensino e aprendizagem, representavam o processo em construção, um movimento de permanência e mudança, no qual se materializavam, de forma complexa, os fazeres escolares planejados de modo compartilhado. Dessa maneira, a prática pedagógica caminhava no sentido de:

- dar evidência às brincadeiras que as crianças já haviam sugerido em sala;

- pedir que os alunos pesquisassem em casa, com os adultos com que convivem (pais, avós, entre outros), outras brincadeiras que eles brincavam nas suas infâncias;

- fazer com que os alunos pesquisassem em livros ou em outros materiais impressos;

II. Segundo Rosa (200 I), quadro produzido em I560, e mostra cerca de 250 personagens participando de 84 brincadeiras. Acredita-se que Bruegel pretendeu fazer uma crítica aos líderes governantes da cidade e da Igreja da época, mostrando que eles agiam como crianças e não levavam o trabalho a sério.

12. Dentre algumas obras consultadas, podemos citar Cabra cega, Menina no balanço e Meninas pulando corda, de Orlando Teruz; e Futebol, Meninos brincando, Meninos no balanço, Meninos pulando carniça, Meninos soltando pipas e Palhacinhos na gangorra, de Cândido Portinari. 
- após esses três momentos, promover uma socialização e discussão de todas as brincadeiras que apareceram, fazendo com que os alunos tenham contato com elas;

- promover um momento para exposição dos quadros e das atividades vivenciadas. (DIÁRIO DE CAMPO, 4-3-2009).

Esse fragmento expressa a complexidade dos caminhos percorridos no processo de intervenção, ou seja, os movimentos, os conhecimentos, as práticas que atravessariam, de maneira estratégica e tática, a cultura produzida no cotidiano. Nesse caso, mesmo diante da delimitação realizada, a professora se apresentou confusa quanto à utilização dos quadros na proposta, mais especificamente em relação aos momentos em que eles poderiam ser utilizados. Uma providência inicial consistiu em sondar os jogos e as brincadeiras que as crianças do $4^{\circ}$ ano conheciam e, consequentemente, os que mais praticavam. Uma das atividades iniciais da professora foi fazer perguntas a cada criança e construir um cartaz com as respostas apresentadas por elas. Dentre as atividades que a turma citou, apareceu desde futebol, queimada, amarelinha e pique-esconde, até video games, entre outras que não conhecíamos, como encantado, guerra dos mundos e pique-sardinha.

Incorporando o universo de vivência das crianças à prática pedagógica, pudemos atualizar nossos conhecimentos e, além disso, constituir as aulas de Educação Física como espaços de construções coletivas, exigindo um processo de implicação dos praticantes envolvidos. ${ }^{13}$ Com o intuito de conhecer novas atividades e ampliar nossos repertórios, começamos, a partir daquele cartaz, a dar ênfase às atividades que menos conhecíamos, buscando percebê-las com base na explanação dos próprios alunos. Cada criança deveria escolher uma atividade presente no cartaz e explicá-la, com o objetivo de ser vivenciada pela turma, conforme demonstra o trecho do diário de campo: ${ }^{14}$

\begin{abstract}
Ao final da aula, a professora fez as seguintes colocações: 'Como o grupo é muito grande, tivemos que fazer adaptações.[...] conseguimos fazer o jogo usando os números para identificá-los [...]. Agora a gente pode pensar outras possibilidades, por exemplo: o que pode acontecer com quem conseguir segurar a bola? E quando for queimado? Podemos criar outras coisas, para além das próprias regras do jogo original, para ir adequando. (DIÁRIO DE CAMPO, 6-3-2009).
\end{abstract}

13. Santos (2005) enfatiza que não há possibilidade de ressignificação pedagógica, no intuito de produzir outras possibilidades de atuação, sem uma participação essencial e experiencial do sujeito.

14. Essa metodologia permitiu, inicialmente, a vivência das brincadeiras: mamãe e os lobos, guerra dos mundos, o rato e o gavião, cai no poço e pique-bandeira. 
O uso das tarefas coletivas remeteu a um maior envolvimento e compromisso por parte das crianças, com as experiências produzidas durante o desenvolvimento do projeto e da pesquisa. Entretanto, algumas meninas apresentaram uma postura de resistência em relação ao espaço-tempo da aula de Educação Física, como nos mostra o fragmento do diário de campo:

$[\ldots .$.$] a professora [\ldots]$ distribui uma tarefa específica ao entender que as meninas não haviam colaborado com a aula passada: 'As pessoas que receberam essa fichinha, é para fazer um texto, pensando no que aconteceu na última aula: Hoje estou sem Educação Física porque... E nós [referindo-se ao restante da turma] vamos sair'. As meninas, exceto uma delas, não fizeram a tarefa pedida. Confeccionaram, na verdade, mensagens que desafiavam a professora $[. .$.$] diziam que a odiavam [...] e que nunca iriam gostar dela. (DIÁRIO$ DE CAMPO, 19-3-2009).

comportamento de resistência astuciosa apresentado pelas alunas gerou impaciência e frustração. Porém, diante de tal situação, começamos a questionar os alunos sobre suas diferenças e o respeito ao outro, focalizando nosso fazer no trato com as questões dos valores e atitudes. Foram planejadas e desenvolvidas diversas situações intencionando potencializar a capacidade de agir cooperativamente. A forma a que nos referimos implicou inserir os alunos nas atividades, privilegiando princípios democráticos, de maneira que eles pudessem participar de forma ativa e propositiva nas aulas.

A partir da listagem de jogos e brincadeiras sugeridos pela turma, executamos uma sequência de cinco atividades: mamãe e os lobos, guerra dos mundos, o rato e o gavião, cai no poço e pique-bandeira. Nessas aulas, os alunos, primeiramente, explanavam a atividade proposta, enquanto os demais prestavam atenção às suas devidas recomendações. Após introduzidas as informações e as condições básicas, a atividade era iniciada e acompanhada de possíveis reflexões e reconstruções. Essa foi uma dinâmica constante nas aulas.

Após a primeira sondagem, organizamos mais duas pesquisas com a turma. A primeira objetivou o resgate dos jogos e brincadeiras vivenciados pelos adultos em suas infâncias, provocando o diálogo com outras gerações de sua família e, por sua vez, demonstrando, assim como na obra de Bruegel, (des)continuidades das práticas corporais.

$\mathrm{Na}$ segunda pesquisa, fomos à biblioteca para que a turma pesquisasse nos livros ou em outros materiais impressos. Formaram-se grupos de quatro componentes, que receberam instruções para selecionar duas brincadeiras, que deveriam ser explicadas em forma de redação.

Com essas tarefas iniciais, sistematizamos a continuidade no trato com o conteúdo, fazendo relações entre as obras de arte. A partir da leitura dos textos de 
Carvalho (2007), França (2004), Rosa (200 I ) e Kishimoto (2007), ${ }^{15}$ com a professora, identificamos a conceituação de jogo, brinquedo e brincadeira e suas implicações para o ensino, bem como a necessidade da construção de um segundo cartaz que materializasse os dados coletados nas pesquisas com os alunos, como mostram os extratos do diário de campo.

Mas não sei se eu faço com eles um quadro. Por exemplo, boneca: boneca é o quê? É uma brincadeira com o quê? Com material? Com o corpo? Tentar ver se a gente consegue chegar a algo nesse sentido. Tenho medo da dinâmica do cartaz ficar muito demorada. Melhor trazer delimitadas as categorias e promover uma maior reflexão em cima das brincadeiras. (PROFESSORA DE EDUCAÇÃO FÍSICA, 9-3-2009).

Discussões interessantes surgiram entre as crianças, como: 'Queimada é só com o corpo? Precisa de mais alguma coisa? Precisa de bola!'. Durante as discussões a professora [...] fez intervenções para explicar melhor a dinâmica das mesmas. (DIÁRIO DE CAMPO, I7-3-2009).

Nesse contexto, o conteúdo jogos e brincadeiras foi categorizado em: a) brincadeiras com brinquedos; b) brincadeiras com o corpo; e c) brincadeiras com materiais. Nos espaços-tempos de planejamento com a professora, passamos a discutir as possibilidades que o conteúdo jogos e brincadeiras trazem para as aulas de Educação Física. ${ }^{16}$

Com base em Ferreira (2006), vimos que, quando a criança brinca, amplia a sua capacidade corporal, a percepção, a relação com o outro, descobre o mundo e conhece leis e regras. Tornar o jogo objeto de intervenção nas aulas de Educação Física é uma forma profícua de assumir outra racionalidade para esse espaço-tempo, que associa interesses e necessidades das crianças para favorecer o desenvolvimento de diversas linguagens presentes na escola.

Vygotsky ( 1991) argumenta que o brincar se configura como uma atividade humana criadora, na qual imaginação, fantasia e realidade interagem na produção de novas possibilidades de interpretação, de expressão e de ação pelas crianças, assim como de novas formas de construir relações sociais com outros sujeitos.

De acordo com Borba (2007), o brincar e o jogar são espaços de apropriação e constituição, pelas crianças, de conhecimentos e habilidades no âmbito das práticas corporais, da linguagem, da cognição, dos valores e da sociabilidade.

15. Segundo Kishimoto (2007), o jogo incorpora a imagem e o sentido que cada sociedade the atribui. Esse aspecto nos mostra por que, dependendo do lugar e da época, ele assume significações distintas.

16. Sobre a importância do jogo e da brincadeira nas aulas de Educação Física, porém no contexto da educação infantil, ver trabalhos de Andrade Filho (2008) e Nunes (2007). 
Esses conhecimentos se tecem nas narrativas do dia a dia, constituindo os sujeitos e a base para muitas aprendizagens e situações em que é necessário o distanciamento da realidade cotidiana, o pensar sobre o mundo e interpretá-lo de novas formas. Ao brincar e jogar, as crianças vão se constituindo como sujeitos de sua experiência social, organizando com autonomia suas ações e interações, elaborando planos e formas de ações conjuntas, criando regras de convivência social e de participação nas brincadeiras.

O trato com a brincadeira e o jogo seria uma possibilidade de compreender a criança como sujeito que produz histórias e culturas com linguagem própria, a infantil, indo além da capacidade de visualizá-la apenas como aluno.

As leituras sobre jogos e brincadeiras nos possibilitaram uma relação mais específica com a proposta de trabalho, na qual pudemos aprofundar a interdisciplinaridade entre o conteúdo proposto e as obras de arte.

No desenvolvimento com a primeira categoria, brincadeiras com o corpo, foram vivenciadas atividades como torre, estrela, caça ao tesouro, polícia e ladrão, pique-rabo, como explicitado a seguir:

A atividade de hoje chamava-se 'Estrela': quem está no centro da roda, formada pelos alunos, deve tentar sair. A atividade foi sugerida, e apontada no cartaz, por uma das alunas, que ficou encarregada de explicá-la. (DIÁRIO DE CAMPO, 14-4-2009).

Nesse cenário, elaboramos a aula de exibição das obras de arte, com a intenção de relacionar com os quadros, pesquisados no início do processo, sobre os jogos e brincadeiras que já havíamos estudado. Na sala de vídeo, retomamos o processo de aprendizagem, detalhando a atividade e a data em que foram retratadas as obras; discutimos também outras formas de realização, relacionando as obras com o que havíamos vivenciado em nossas aulas; e, por fim, questionamos se as crianças conheciam as brincadeiras a partir de outras referências ou nomes, conforme relato da professora:

Nós estamos fazendo algumas pesquisas, procurando algumas informações sobre jogos e brincadeiras presentes em nosso cotidiano, nossa cultura, ou seja, como eles aparecem e como é essa questão no nosso dia a dia [...]. Hoje nós vamos trazer para vocês algumas imagens de pintores famosos que remetem um pouco sobre jogos e brincadeiras, em variadas épocas. (PROFESSORA DE EDUCAÇÃO FÍSICA, 5-5-2009).

Ao projetar em power point o quadro Meninos soltando pipas, de Candido Portinari, os alunos associaram a pipa ao papagaio e o caixote e, ao mesmo tempo, produziram narrativas sobre as vivências com esse brinquedo. Especificamente no quadro de Bruegel, ao final da aula, pedimos que as crianças o observassem 
detalhadamente e anotassem a maior quantidade de brincadeiras que conseguissem identificar, para que pudéssemos relacioná-las com as categorias construídas no cartaz Brincadeiras Infantis.

Afixamos o cartaz ao lado da projeção do quadro Jogos Infantis, possibilitando o agrupamento e cruzamento das atividades destacadas pelas crianças. A partir desse processo, concentramo-nos em discutir e experimentar as atividades que mais apareceram nas anotações. Dentre elas destacam-se, na categoria brincadeiras com o corpo: carniça, cadeirinha e balança caixão; e, na categoria brincadeiras com materiais: cabo de guerra. Como eram atividades que as crianças pouco vivenciavam, apresentamos as suas dinâmicas, adaptando-as para as condições de aula.

Com o objetivo de dar ênfase à categoria brincadeiras com brinquedos, solicitamos que os alunos trouxessem um brinquedo de casa. Nossa intenção foi promover um diálogo com os alunos sobre a diferença existente entre os brinquedos construídos pela indústria especializada e os produzidos com materiais alternativos. Chamamos a atenção para as possibilidades apresentadas pela construção de brinquedos, bem como para a necessidade de se resgatar algumas brincadeiras indicadas pela família, que não eram de conhecimento da turma, como: pé de lata, bilboquê, bolinha de meia, entre outras. A grande quantidade de materiais utilizada, associada às intervenções da professora, facilitou que os alunos se apropriassem dos usos dos brinquedos e não se dispersassem durante as atividades.

Inserimos também outros brinquedos, como corda e peteca, que, apesar de conhecerem, a maioria dos alunos não apresentavam vivências com esses materiais, como mostra o relato:

Na nossa última aula, vocês brincaram um pouco com brinquedos que vocês costumam usar no dia a dia. Mas vocês costumam brincar de pé de lata? De amarelinha? De peteca? De corda? De bilboquê? (PROFESSORA DE EDUCAÇÃO FíSICA). As crianças responderam que não. A professora prosseguiu: Todas essas brincadeiras, ou a maioria delas [...] representam brinquedos de crianças de uma outra geração [...]. Os brinquedos foram ficando diferentes. (DIÁRIO DE CAMPO, 14-5-2009).

Ao nos aproximarmos do fim do trimestre letivo, a professora decidiu fazer uma atividade avaliativa, com base na prática docente construída. Apesar de as ações avaliativas perpassarem todo o processo de ensino, a professora configurou dois momentos específicos. São eles: um diálogo para analisar as aulas; e um registro, em forma de desenho, da atividade que mais gostaram de conhecer.

Em conversa realizada com os alunos na sala, para que pudessem avaliar o processo pedagógico, observamos que suas análises se centralizavam nas questões referentes à falta de organização, à dificuldade em cooperar, ou seja, o modo como os sujeitos foram se envolvendo no processo de intervenção e sua relação com 
a importância de se trabalhar os atributos relacionados com comportamentos e atitudes. Foi possível também observar que a centralização da avaliação se pautava na falta, nas dificuldades, nos problemas enfrentados durante o trimestre.

É preciso ter a leitura da própria característica que a avaliação vem assumindo no contexto escolar, já que, na maioria das vezes, é usada para se definir e diagnosticar os "não saberes", "as ausências", centralizando-se em uma perspectiva negativa e excludente. ${ }^{17}$ Santos $(2005,2008)$ destaca que, ao ser assumida pelos praticantes escolares como nota e conceito, ou seja, como ato de medida que se projeta ao final de um processo, a avaliação ganha os contornos de uma leitura binária, centralizado-se no "erro"/"acerto", "saber"/"não saber" que acaba, por sua vez, evidenciando os processos hierarquizadores e excludentes.

No entanto, fundamentando-nos numa dimensão prospectiva, em um "vir-a-ser", observamos que as reflexões efetuadas pelos alunos precisavam ser mais trabalhadas, já que, como foi destacado, havíamos identificado a necessidade de dedicar maior atenção aos atributos relacionados com o comportamento e atitudes durante o processo de intervenção.

Uma outra questão que não pode ser ignorada é o fato de estarmos tratando de um componente curricular que assume um estatuto epistêmico que privilegia uma outra relação com o saber, ${ }^{18}$ comparada com as demais disciplinas escolares. Para Schneider e Bueno (2005), a Educação Física não privilegia o saber-objeto que pode ser incorporado pela relação epistêmica com os objetos, mas, sim, o saber concretizado por meio do domínio de uma atividade. Depreendemos desse debate que a criança não aprende apenas quando lê, escreve e fala. Aprende também quando se expressa corporalmente, uma vez que o movimentar-se não pode ser considerado apenas natural, espontâneo, biológico; relaciona-se, principalmente, com questões culturais, afetivas e sociais. Alertam que, no trabalho com a Educação Física, mais importante do que conseguir sistematizar uma explicação do que se aprendeu, certamente, é a experiência vivenciada.

17. Para Charlot (2000), uma "leitura negativa" explica o fracasso escolar pelo que o aluno não é, não fez, pelas suas carências; já uma "leitura positiva" presta atenção ao que os alunos fazem, conseguem, sabem da vida.

18. Para Charlot (2000, p.78-79), "a relação com o saber é relação com o tempo. A apropriação do mundo, a construção de si mesmo, a inscrição em uma rede de relações com os outros - 'o aprender' — requerem tempo e jamais acabam. Esse tempo é o de uma história: da espécie humana, que transmite um patrimônio a cada geração; da linhagem que engendrou o sujeito e que ele engendrará. Esse tempo não é homogêneo, é ritmado por 'momentos' significativos, por ocasiões, por rupturas; é o tempo da aventura humana, a da espécie, a do indivíduo. Esse tempo, por fim, se desenvolve em três dimensões, que se interpenetram e se supõem uma à outra: o presente, o passado, o futuro." 
Os conhecimentos com os quais a disciplina Educação Física lida, como os esportes, jogos, danças, lutas e ginástica, são atividades constantemente submetidas a minivariações de situações de aplicação, por isso a dificuldade de expô-las integralmente em forma de enunciados. Fazer com, nesse sentido, indica o tipo de investigação que se pode desenvolver quando se busca compreender o conhecimento que os alunos e alunas conseguiram mais incorporar do que sistematizar em forma de enunciados. (SCHNEIDER; BUENO, 2005, p.40).

Essas reflexões trazem uma gama de indagações que perpassam pelo próprio questionamento sobre o papel da Educação Física no contexto escolar, sua singularidade, significação e papel social. A Educação Física, ao lidar com a relação do saber-domínio que se centraliza na dimensão do fazer com, subverte a forma escolar. A escola é o lugar da palavra, da linguagem, ou de outras formas de simbolização do mundo, do texto, de saberes sistematizados, cujo modo de existência é a linguagem, por isso sua valorização da dimensão falar de em contraposição ao fazer com.

Contudo, se, por um lado, essa disciplina ressignifica o espaço escolar, por outro, tem que se adequar a ele, ou seja, ao mesmo tempo em que a Educação Física opera com as lógicas e procedimentos que oferecem fundamento à forma escolar, como é o caso da nota, também a subverte, na medida em que estabelece a relação do "corpo-sujeito com o mundo, um mundo compartilhado com outros, uma forma incorporada de ser dono de si mesmo e do seu ambiente." (CHARLOT, 2009, p. 244). ${ }^{19}$

A forma de significar o lugar e as possibilidades de usos dos saberes compartilhados pela/na Educação Física, no contexto escolar, perpassa pelo entendimento de sua singularidade/diferenciação, fato esse, de certa forma, sinalizado pelos alunos ao significarem seus aprendizados a partir do saber-relacional, bem como a dificuldade em transformar o saber de domínio em saber-objeto, que deveria ser enunciado pela linguagem, quando perguntados sobre o processo pedagógico.

Apesar dessa dificuldade, percebemos que o fato de a Educação Física privilegiar a dimensão do fazer com, não exclui a possibilidade de se materializar o saberdomínio em saber-objeto, fato esse observado na produção do desenho realizado pelos alunos do $4^{\circ}$ ano. Ao solicitarmos a produção do desenho, possibilitamos que os alunos manifestassem, mediante a transformação de saber-domínio para saberobjeto, as atividades que demarcaram suas experiências corporais. Partimos, assim, das práticas encarnadas no corpo para produzir apropriação de regras e reflexividade, que se manifestaram nos desenhos produzidos pelos alunos.

19. Na visão do autor (2009, p. 234) "não é de se admirar que a Educação Física se confronte com contradições e que suas aulas sejam percebidas como momentos de libertação, de alívio dos constrangimentos e ganhem a fama de 'recreativas'”. Sobre o assunto, o autor salienta: "A Educação Física não é uma disciplina escolar 'como as demais'. E acrescento: felizmente. Não é igual às demais porque ela lida com uma forma do aprender. Em vez de tentar anular ou esconder essa diferença, dever-se-ia destacá-la e esclarecê-la." (CHARLOT, 2009, p. 243). 
Por fim, diante do processo de pesquisa, o que se tornou determinante foram as nossas condições, maiores ou menores, de refletir sobre os fazeres produzidos, que só se realizaram a partir de nossas apropriações. Isso explica porque, muitas vezes, conteúdos e métodos propostos nos currículos/prescrições comuns não representam além do que meras formalidades, ou seja,

[...] é preciso que comecemos a entender [...] pequenos eventos do cotidiano, não como desvios ou falhas no controle das situações, mas como constitutivos da vida e da dinâmica escolares (e da vida geral) e que, portanto, exigem um tratamento diferente [...] ancorando-os mais na vida real e menos nos elementos quantitativos e organizáveis que dela fazem parte. (OLIVEIRA, 2005, p. 121).

\section{CONSIDERAÇÕES FINAIS}

Na elaboração deste trabalho, procuramos responder ao chamado que a produção acadêmica aponta como necessidade, isto é, articulação entre pesquisa e ensino com o cotidiano produzido com os diferentes sujeitos, e com a participação do pesquisador na árdua e desafiante função de mobilizar saberes, investigar e sistematizar a intervenção, no caso, o ensino da Educação Física.

Buscamos a descrição da prática como uma etnografia, que se fez ricamente tecida na simplicidade de quem fez, sentiu e desejou essa experiência de ensino, pois, ao nos dedicarmos a um referencial complexo, como o currículo e o cotidiano, e das abordagens metodológicas de pesquisa, de intervenção e de formação conciliados com a perspectiva do "fazer com", o nosso estudo expressa a responsabilidade com a tradução para o contexto da escola e da Educação Física.

Considerando a prática do ensino de jogos e brincadeiras planejada, desenvolvida e avaliada, em situações e lugares diferenciados, pela professora, pelos pesquisadores e pelas crianças, destacamos a expressão de várias possibilidades para o ensino da Educação Física no nosso contexto.

Compartilhamos das reflexões de Beauchamp, Pagel e Nascimento (2007), quando salientam que é preciso definir o brincar como um modo de ser e estar no mundo; como uma expressão legítima e única da infância, em que o lúdico se expressa como um dos princípios para a prática pedagógica, e a brincadeira, nos tempos e espaços da escola e das salas de aula, como possibilidade para conhecer mais as crianças e as infâncias.

Consideramos que foi possível apreender com a pesquisa e com o ensino: a constituição de uma identidade docente e de pesquisador, aproximada aos princípios da proposta colaborativa de pesquisa, cuidando de grandes tensões nessa esfera, como o levantamento de problemas observados e o surgimento da necessidade de investigá-los; a busca de compreensão e transformação da prática, o que nos fez 
transitar entre a perspectiva de projeto de investigação e projeto de intervenção e de formação; o reconhecimento político da diferenciação entre os papéis de pesquisadores e professora, bem como da participação das crianças como sujeitos; o estabelecimento de comprometimentos e promoção da atitude investigativa com todos os envolvidos, de modo que o ensino e a aprendizagem se transformaram em pesquisa; o fomento aos processos reflexivos, com o registro e a partilha de decisões como um exercício coletivo de estudos, discussões e práticas, por meio da construção de uma rede de conversações e ações. Enfim, um conjunto de princípios importantes para provocar o debate sobre o assunto.

Caminhamos na direção de uma proposta de escola e de Educação Física que, sobremaneira, se fez interdisciplinar com diferentes linguagens, problematizadora, dialógica, prática, reveladora das potencialidades dos sujeitos crianças, professora e pesquisadores. A clareza das intencionalidades do projeto pedagógico vivido potencializou as forças para os enfrentamentos na e da escola brasileira.

Por fim, ressaltamos que a escola, com uma dinâmica interativa que indica muito mais do que aparenta, necessita de idas e vindas ao seu cotidiano, em um movimento que compartilhe fazeres de maneira colaborativa, para a compreensão das especificidades de cada fazer, especialmente da Educação Física.

\section{Shared knowledge in the teaching of games and fun activities: way/of doing art in physical education}

ABSTRACT: The current text describes a pedagogical project for teaching Physical Education developed from the content of games and fun activities, in an elementary municipal school, in a $4^{\circ}$ grade group. It takes the perspective of studies with the everyday life and uses as instruments for data production, observation, photographic and filmic record and interviews. The paper justifies the possibility of building a teaching practice mediated by a collaborative research of the space-time in school, in the process of sharing pedagogical practices recognizing the complexity, the plurality and singularity of school actions, especially the ones produced in Physical education lessons.

KEYWORDS: Physical education; games and fun activities; shared knowledge; intervention.

\section{Saberes compartidos en enseño de juegos:}

maneiras/artes de hacer en la educación fisica

RESUMEN: El presente texto describe un proyecto pedagógico para lo enseño de la Educación Física, desenvuelto a partir de lo contenido juegos, en una escuela municipal de enseño fundamental, con una turma del $4^{\circ}$ año. Asume la perspectiva de los estudios con los cotidianos y utiliza, como instrumentos para producción de los datos, la observación, lo registro fotográfico y filmico y la entrevista. Justifica la posibilidad de construcción de una práctica docente 
mediada por una búsqueda colaborativa en lo espacio-tiempo escolar en lo proceso de compartir las prácticas pedagógicas, reconociendo la complexidad, la pluralidad y la singularidad de las acciones escolares, en especial las producidas en las clases de Educación Física. PALABRAS CLAVE: Educación física; juegos; saberes compartidos; intervención.

\section{REFERÊNCIAS}

ALVES, N.; GARCIA, R. L. Continuando a conversa: apresentando o livro. In: FERRAÇO, C. E.; PEREZ, C. L. V.; OLIVEIRA, I. B. (Org.). Aprendizagens cotidianas com a pesquisa: novas reflexões em pesquisa nos/dos/com os cotidianos das escolas. Petrópolis: DP et Alii, 2008. p. 9-14.

ANDRADE FILHO, N. F. Movimento corporal humano: objeto de estudo/ensino exclusivo ou específico da Educação Física para a educação infantil? In: ; SCHNEIDER,

O. (Org.). Educação Física para a educação infantil: conhecimento e especificidade. São Cristóvão: Editora da UFS, 2008. p. 177-225.

BEAUCHAMP, J.; PAGEL, S. D.; NASCIMENTO, A. R. (Org.). Ensino fundamental de nove anos: orientações para a inclusão da criança de seis anos de idade. Brasília: MEC, 2007.

BONDÍA, J. L. Notas sobre, a experiência e o saber da experiência. Revista Brasileira de Educação, Campinas, n. 19, p. 20-28, jan./abr. 2001.

BORBA, A. M. A infância na escola e na vida: uma relação fundamental. In: BEAUCHAMP, J.; PAGEL, S. D.; NASCIMENTO, A. R. Ensino fundamental de nove anos. Brasília: MEC, 2007. p.33-46.

CARVALHO, J. M. Cotidiano escolar como comunidade de afetos. Petrópolis: DP et Alii, 2009.

CARVALHO, L. D. Culturas infantis: universalidade e diversidade. In: ENCONTRO ANUAL DA ASSOCIAÇÃO NACIONAL DE PÓS-GRADUAÇÃO E PESQUISA EM CIÊNCIAS SOCIAIS, 31 ., 2007, Caxambu. Anais... Caxambu: Associação Nacional de Pós-Graduação e Pesquisa em Ciências Sociais, 2007.

CERTEAU, M. A invenção do cotidiano I: artes de fazer. 8. ed. Petrópolis: Vozes, 1994.

CHARLOT, B. Da relação com o saber: elementos para uma teoria. Porto Alegre: Artes Médicas Sul, 2000.

Ensinar a educação física ou ajudar o aluno a aprender o seu corpo-sujeito? In: DANTAS JUNIOR, H. S.; KUHN, R.; RIBEIRO, S. D. D. Educação Física, esporte e sociedade: temas emergentes. São Critóvão: Editora da UFS, 2009. v.3, p.23I-246. 
FALCÃO, J. M. Ensino e pesquisa com o cotidiano: as artes de fazer um currículo da Educação Física em uma escola municipal de ensino fundamental de Vitória-ES. 2009. 176 f. Dissertação (Mestrado em Educação Física) - Centro de Educação Física e Desportos, Universidade Federal do Espírito Santo, Vitória, 2009.

FERRAÇO, C. E. A pesquisa em educação no/do/com o cotidiano das escolas. In: PEREZ, C. L. V.; OLIVEIRA, I. B. (Org.). Aprendizagens cotidianas com a pesquisa: novas reflexões em pesquisa nos/dos/com os cotidianos das escolas. Petrópolis: DP et Alli, 2008.

Eu, caçador de mim. In: GARCIA, R. L. (Org.). Método: pesquisa com o cotidiano. Rio de Janeiro: DP\&A, 2003. p. I57- 175.

FERREIRA, A. Criar e brincar com Portinari: uma abordagem da arte por meio de atividades lúdicas e interdisciplinares. Rio de Janeiro: Nova Razão Cultural, 2006.

FRANÇA, L. C. Z. Mergulhos fascinantes nas imagens, nos outros e em nós mesmos. In: ENCONTRO DE PESQUISA EM EDUCAÇÃO DA REGIÃO CENTRO-OESTE, 7., 2004, Goiânia. Anais... Goiânia: UFG, 2004. v.l.

LOCATELLI, A. Saberes docentes na formação de professores de Educação Física: um estudo sobre práticas colaborativas entre universidade e escola básica. 2007. 32 I f. Dissertação (Mestrado em Educação) - Centro de Educação, Universidade Federal do Espírito Santo, Vitória, 2007.

KISHIMOTO, T. M. O jogo e a educação infantil. In: (Org.). Jogo, brinquedo, brincadeira e educação. São Paulo: Cortez, 2007. p. I3-43.

MOLINA, R. K.; MOLINA NETO, V. A prática pedagógica do professorado de educação Física no cotidiano escolar, pesquisar e aprender: metaponto de vista. In: MOLINA NETO, V. (Org.). Quem aprende? pesquisa e formação em educação física escolar. ljuí: Ed. da Unijuí, 2009. p. 13-36.

Pesquisa qualitativa em educação física escolar: a experiência do F3P-EFICE. In: MOLINA NETO, V.; BOSSLE, F. (Org.). O ofício de ensinar e pesquisar na Educação Física escolar. Porto Alegre: Sulina Meridional, 20 I0. v. I, p.9-36.

NUNES, K. Práticas curriculares da Educação Física na educação infantil: um estudo de caso. 2007. I 40 f. Dissertação (Mestrado em Educação Física) - Centro de Educação Física, Universidade Federal do Espírito Santo, Vitória, 2007.

OLIVEIRA, I. B. Currículos praticados: entre a regulação e a emancipação. Rio de Janeiro: DP\&A, 2005.

ROSA, N. S. Brinquedos e brincadeiras. São Paulo: Moderna, 200I.

SANTOS, W. Currículo e avaliação na Educação Física: do mergulho à intervenção. Vitória: Proteoria, 2005. 
Currículo e avaliação na educação física: práticas e saberes. In: SCHNEIDER, O. (Org.). Educação Física esporte e sociedade: temas emergentes. São Cristovão: Ed. da UFS, 2008. v. 2. p.87-106.

SANTOS, W. dos; NUNES, K. R.; FERREIRA NETO, A. Educação física na educação básica: pontos de encontro. In: KHUN, R. Educação Física, esporte e sociedade: temas emergentes. Aracaju: UFS, 2009. v. 3. p. 18I-205.

SCHNEIDER, O.; BUENO, J. G. A relação dos alunos com o saber compartilhado nas aulas de educação física. Movimento: revista da Escola de Educação Física, Porto Alegre, v. I I, n. I, p. 23-46, jan./abr. 2005.

SCHNEIDER, O. et al. A relação dos alunos com os saberes no ensino médio: notas para compreendermos a escola e a Educação Física. In: DANTAS JUNIOR, H. S.; KUHN, R.; RIBEIRO, S. D. D. Educação Física, esporte e sociedade: temas emergentes. São Critóvão: Ed. da UFS, 2009. v. 3, p.77-94.

VYGOTSKY, L. S. A formação social da mente: o desenvolvimento dos processos psicológicos superiores. 4. ed. São Paulo: Martins Fontes, 1991.

Recebido: 26 dez. 2010

Aprovado: 18 abr. 201 I

Endereço para correspondência:

Júlia Miranda Falcão

Av. Fernando Ferrari s/n — Goiabeiras (ES)

PROTEORIA/CEFD/UFES

29060-900 